\title{
Solar Radiation Potential at Four Sites of Nepal
}

\author{
Khem N. Poudyal ${ }^{1}$, Binod K. Bhattarai ${ }^{1}$, Balkrishna Sapkota ${ }^{1}$, Berit Kjeldstad $^{2}$ \\ ${ }^{1}$ Institute of Engineering, Tribhuvan University, Kathmandu, Nepal \\ ${ }^{2}$ Department of Physics, Norwagian University of Science and Technology, Norway
}

\begin{abstract}
The intensity of solar radiation available at the horizontal surface are measured by a CMP6 Pyranometer in Biratnagar $\left(26.45^{\circ} \mathrm{N}, 87.27^{\circ} \mathrm{E}\right)$, Pokhara $\left(28.22^{\circ} \mathrm{N}, 83.32^{\circ} \mathrm{E}\right)$, Kathmandu $\left(27.72^{\circ} \mathrm{N}, 85.32^{\circ} \mathrm{E}\right)$ and Lukla $\left(26.69^{\circ} \mathrm{N}, 86.73^{\circ} \mathrm{E}\right)$, which are $72 \mathrm{~m}, 800 \mathrm{~m}, 1350 \mathrm{~m}$, and $2850 \mathrm{~m}$, above from the sea level.

This paper compares the seasonal and altitude variations of total solar radiation measured at above mentioned sites. The maximum total solar radiation of about $704.51 \mathrm{~W} / \mathrm{m}^{2}, 815.97 \mathrm{~W} / \mathrm{m}^{2}$ 777.27 W/m $\mathrm{m}^{2}$ and $914.03 \mathrm{~W} / \mathrm{m}^{2}$, are observed in Biratnagar, Pokhara, Kathmandu, and Lukla respectively. Solar radiation available in any location is affected by topography and pollution. It is found that the more solar energy is available during spring than in summer in Lukla. The solar radiation is observed higher in Pokhara than in Kathmandu. It might be due to absorption of solar energy by air pollutants which are higher in Kathmandu as compared to Pokhara.In addition we also discussed the diurnal variation of measured and calculated data of solar radiation on clear sky day. The annual average solar energy measuring $4.95,5.44,5.19$ and $4.61 \mathrm{kWh} / \mathrm{m}^{2} /$ day is found in Biratnagar, Pokhara Kathmandu and Lukla respectively.
\end{abstract}

Keywords: Total radiation, potential, seasonal variation, altitude

\section{Introduction}

The solar energy arriving in the earth's surface is in the form of electromagnetic radiation and mostly lies in the wavelengths of 0.3 to 3.0 micrometer. The total solar radiation after entering the earth's atmosphere is absorbed and scattered by air molecules, clouds, and aerosols.

The utilization of solar energy, like any other natural resource, requires detailed information on its availability. The study of solar radiation should incorporate solar radiation and local weather condition. The total solar radiation potential will be milestone for designing and predicting the performance of solar energy equipment and solar energy potential. (Sukhera et.al 1987). It is known that the higher the altitude, greater the total solar radiation under the clear and intermediate sky conditions, but under the overcast days the solar radiation is very low in comparison with sunny days (Becker, Boyd, 1954. Oki et.al 2003). The solar radiant energy on the earth's surface is a requirement not only in the studies of climate change, environmental pollution but also in agriculture, hydrology, food industry and promotion of solar energy development programs (Iqbal, 1983).

Continuous and long term solar radiation data are not available in Nepal. But short term monitoring and utilization of solar radiation has been done by Royal Nepal Academy of Science and Technology (RONAST) in collaboration of JICA, Japan. They installed the $4 \mathrm{~kW}$ prototype and $40 \mathrm{~kW}$ solar photovoltaic panels at Sunderighat, Kirtipur and Bode Bhaktapur for the purpose of water pumping in 1992 and 1995 respectively (Bhandari, 1996). 
Center for Energy Studies, IOE TU with support from Alternative Energy promotion centre (AEPC) had conducted Solar Energy monitoring in 2000/01 in two districts Kathmandu and Sunsari. According to the study, the annual average solar energy of 4.35, 3.49, 3.76, 5.12 and $2.93 \mathrm{kWh} / \mathrm{m}^{2} /$ day were measured at Budhanilkantha, Kakani, Phulchowki, Pulckowk and Thankot respectively. Similarly, in Sunsari district the annual average solar energy 3.68, 5.09, $3.18,4.05$, and $4.32 \mathrm{kWh} / \mathrm{m}^{2} /$ day was found at Dharan, Inhruwa, Itahari, Mahendranagar and Prakashpur respectively (CES, 2001).

Solar and Wind Energy Resource Assessment (SWERA) reported an annual average of $4.7 \mathrm{kWh} / \mathrm{m}^{2} /$ day solar energy is available in Nepal (SWERA, 2006).

This study indicates that Nepal is rich in solar energy. But, to confirm this statement long term continuous solar energy data are required. Thus, the main objectives of this study are to observe a continuous intensity of solar radiation and analyze the data. The other objective is to study the effect of topography and air pollutant as the solar radiation.

\section{Measuring Sites}

We have selected the appropriate sites for measuring solar radiation. These sites cover the main three topography of Nepal like Plain low land region, Hills and High Mountains for the measurement of total solar radiation at the horizontal surface. These selected sites cover the ranges of altitude from $72 \mathrm{~m}$ to $2850 \mathrm{~m}$. The figure 1 shows the location of selected sites. The brief introduction of monitoring sites is given below.

Biratnagar lies at eastern part of Nepal at the altitude of $72 \mathrm{mfrom}$ the sea level. Its climate is closer to tropical and extremely hot up to the $40^{\circ} \mathrm{C}$ and humid in summer and very cold and fuggy in winter. In winter, the temperature ranges from 10 to $20^{\circ} \mathrm{C}$.

Pokhara is located at the altitude of $800 \mathrm{~m}$, a Sub-Metropolitan City. Its climate is sub-tropical and moderate and the precipitation is about $4000 \mathrm{~mm}$ which is the highest in Nepal. The maximum and minimum temperature ranges from 25 to $35^{\circ} \mathrm{C}$, and 2 to $15^{\circ} \mathrm{C}$, in summer and winter respectively.

Kathmandu is the capital city located at an altitude of $1350 \mathrm{~m}$. It is a small with a bowl-shaped valley. This Valley falls under the Warm Temperate Zone. The average temperature during the summer and winter season are 28 to $30^{\circ} \mathrm{C}$. and 3 to $10.1^{\circ} \mathrm{C}$ respectively. The average precipitation is about $1,024.0 \mathrm{~mm}$. The air quality of Kathmandu Valley is deteriorating. The visibility level decrease at the rate of $1.2 \mathrm{~km} /$ year. This obviously shows that fine particulate level in the Valley has increased at a very high rate. This may be associated with road traffic and various types of construction works (Sapkota, 2009).

Lukla lies near to Mount Everest area at an altitude of $2850 \mathrm{~m}$. Its climate is sub-tropical, wet summers and chilly, dry winters are mainly affected by its altitude and the summer monsoon season. The temperature ranges about 4 to $27^{\circ} \mathrm{C}$ and -15 to $6{ }^{\circ} \mathrm{C}$ on summer and winter respectively. 


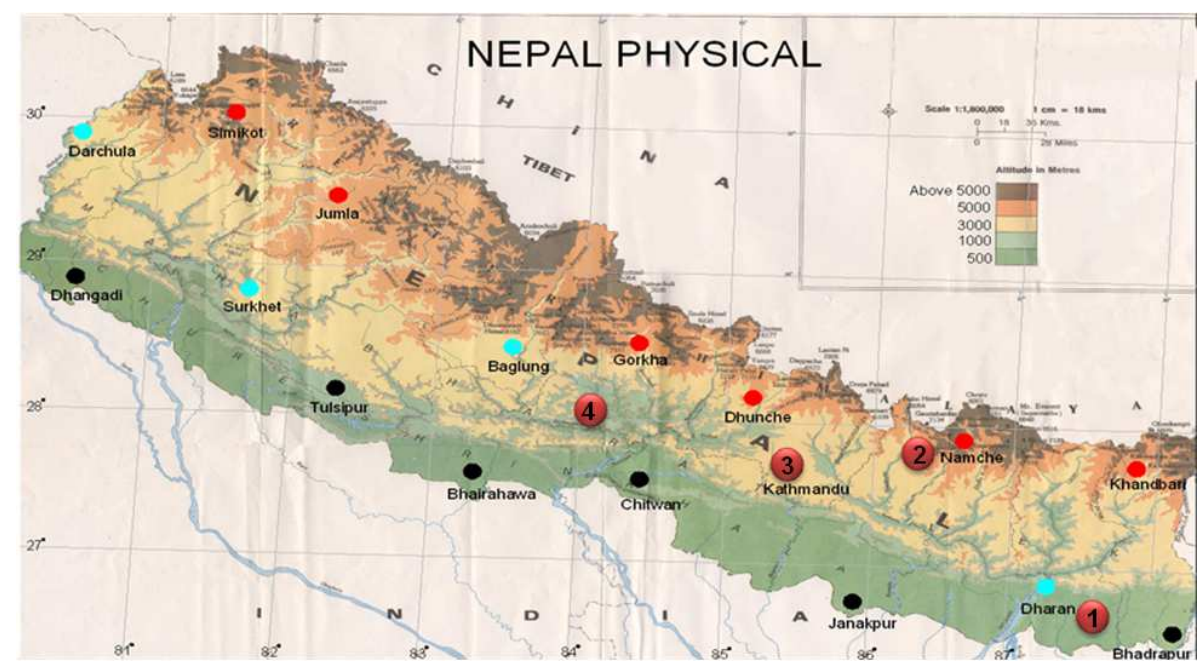

Fig. 1: The map of Nepal showing the measuring stations:

1-Biratnagar, 2-Lukla, 3-Kathmandu and 4-Pokhara

\section{Instrument and Methods}

The total solar radiation on a horizontal surface was measured using Kipp and Zonen CMP6 Pyranometer in four sites of Nepal. The instruments were installed in Biratnagar $\left(26.45^{\circ} \mathrm{N}\right.$, $\left.87.27^{\circ} \mathrm{E}\right)$, Lukla $\left(26.69^{\circ} \mathrm{N}, 86.73^{\circ} \mathrm{E}\right)$, Kathmandu $\left(27.7^{\circ} \mathrm{N}, 85.5^{\circ} \mathrm{E}\right)$ and Pokhara $\left(28.22^{\circ} \mathrm{N}\right.$, $83.32^{\circ} \mathrm{E}$ ) which are $72 \mathrm{~m}, 2850 \mathrm{~m}, 1350 \mathrm{~m}$ and $800 \mathrm{~m}$ above from the sea level. The spectral range of instrument is from $310 \mathrm{~nm}$ to $2800 \mathrm{~nm}$. The operating temperature is from $-40{ }^{\circ} \mathrm{C}$ to $80^{\circ} \mathrm{C}$. Similarly, the instrument sensitivity and field of view are 5 to $15 \mu \mathrm{V} / \mathrm{W} / \mathrm{m}^{2}$ and $180^{\circ}$ respectively.

All the measuring data are recorded by LOGBOX SD data logger within a minute resolution for 24 hours. It features low noise, high resolution and low power consumption. It can be used in all weather conditions. It collects the data at real time for the needs of meteorology and slow signal analysis. For data logging $128 \mathrm{~KB}$ of memory is available. We can insert the SD memory card for long-term data storage. For the communication LOGBOX uses either RS232 or RS485 communication port (Kipp and Zonen 2008).

The measured solar radiation is compared with calculated data of solar radiation by using Spectral Integration Model data Table 7.2.1 (Iqbal, 1983, pp172) under cloudless skies at the horizontal surface.

In this paper, these calculated values are compared with measured values. The cause of discrepancy is discussed in appropriate section.

The cloud transmittance factor (cf) is measured by NILUUV irradiance meter. This comparative study will help to estimate the solar radiation potential in clear sky days. In this paper, we compare the seasonal variation as well as altitude variation of total solar radiation which are very important factors to estimate the solar energy potential at measuring sites .The cloud transmittance factor $\mathrm{cf}$ is measured by NILUUV irradiance meter. This device is a six chhanel radiometer designed to measure hemispherical irradiances as well as cloud transmittance factor on a plane surface. The different effects of cloud on total solar irradiance and UV irradiance are 
estimated on the basis of cloud transmittance factor. The measured $\mathrm{cf}$ is utilized to explain the availability of solar energy in different locations. It is the ratio of measured radiation to the calculated clear sky radiation no aerosols, zero surface albedo. It is measured in percentage. The range of cloud transmittance factor value is from 0 to 1 (Høiskar et.al. 2003).

\section{Results and Discussion}

\subsection{Diurnal Variation of Solar Radiation at Four Sites of Nepal}

Figure 4.1(a) shows the measured data of diurnal variation of solar radiation in Biratnagar on $11^{\text {th }}$ February, 2010. However the maximum solar radiation $704.51 \mathrm{~W} / \mathrm{m}^{2}$ is found at noon time. In the figure, the measured values are compared with calculated values of clear sky condition. It shows that measured values are $47.3 \%$ less than calculated value. The correlation coefficient, standard deviation and P-values are 0.953, 93.08 and 0.0001 respectively. These statistical analyses show that the quality of the measured data is good.

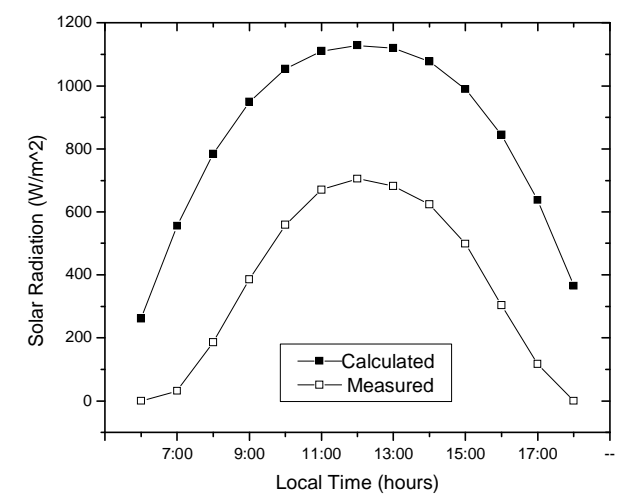

(a) Biratnagar

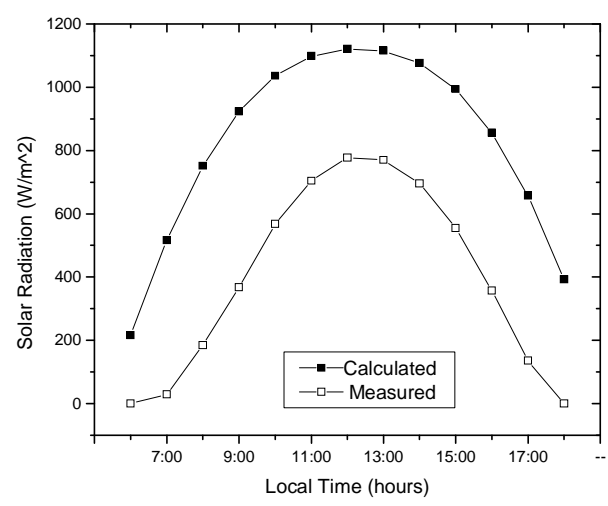

(c) Kathmandu

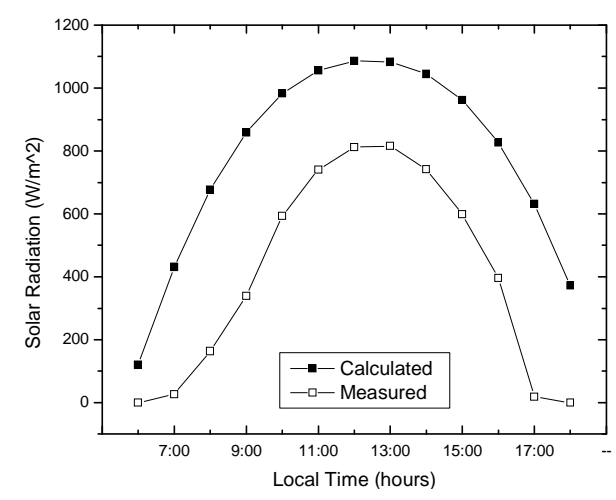

(b) Pokhara

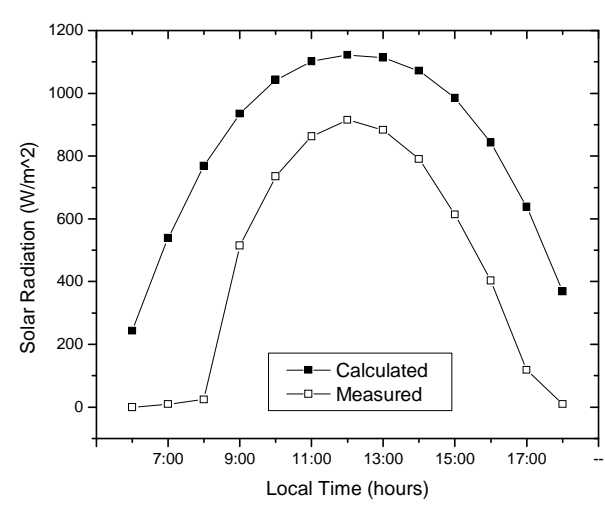

(d) Lukla

Fig. 4.1: Diurnal Variation of Total Solar Radiation at four sites 
Figure 4.1(b) indicates the measured data of diurnal variation of global solar radiation in Pokhara on $11^{\text {th }}$ February, 2010. Even at the winter season the maximum solar radiation $815.97 \mathrm{~W} / \mathrm{m}^{2}$ is found at 13:00. It shows that measured values are $37.31 \%$ less than calculated values. The correlation coefficient, standard deviation and P-values are $0.92,133.32$ and 0.0001 respectively. These statistical analyses show that the quality of the measured data is good.

Figure 4.1(c) shows the measured data of diurnal variation of solar radiation in Kathmandu on $11^{\text {th }}$ February, 2010. However, the maximum values of measured total solar radiation 777.27 $\mathrm{W} / \mathrm{m}^{2}$ is found at noon time. It indicates that measured data is $37.85 \%$ less than calculated values. The correlation coefficient, standard deviation and P-values are 0.94, 101.87 and 0.0001 respectively. These statistical analyses show that the quality of the measured data is relevalent.

Figure 4.1(d) show the measured data of diurnal variation of global solar radiation in Lukla on $11^{\text {th }}$ February, 2010. However, there was maximum solar radiation $914.03 \mathrm{~W} / \mathrm{m}^{2}$ found at noon time. In the figure, the measured values are compared with calculated values in clear sky condition. It shows that measured values are $31.41 \%$ less than calculated values. The statistical analyzes the data and it gives the correlation coefficient in between measured value and calculated value of solar radiation of 0.920 . Similarly, the standard deviation and P-value of the measured data 121.62 and the P-value 0.0001 are found respectively. Hence, statistical analysis indicates that the measured data is significant.

\subsection{Daily Variation of Solar Energy at Four Sites of Nepal}

Figure 4.2(a) shows that there is high fluctuation of solar energy in Biratnagar. The solar energy varies from $2.49 \mathrm{MJ} / \mathrm{m}^{2} /$ day to $14.39 \mathrm{MJ} / \mathrm{m}^{2} /$ day during the month of January whereas the overall average energy is about $9.13 \mathrm{MJ} / \mathrm{m}^{2} /$ day.

Figure 4.2(b) shows that there is no more solar energy fluctuation in Pokhara in a whole month. It reflects that the local weather condition remains stable as compared to other stations. In this site the solar energy varies from $6.95 \mathrm{MJ} / \mathrm{m}^{2} /$ day to $16.22 \mathrm{MJ} / \mathrm{m}^{2} /$ day. The overall average energy is about $14.32 \mathrm{MJ} / \mathrm{m}^{2} /$ day. The average value of cloud transmittance factor is about $49.04 \%$ in 9 days out of 31 days.

Figure 4.2(c) shows that there is slightly fluctuation in the solar energy in Kathmandu from January 1 to 5 after that the energy trend line is uniform from 5 to 13 and after the $13^{\text {th }}$ January it fluctuates with high rate from the certain interval of day. It means that the solar energy varies from $10.45 \mathrm{MJ} / \mathrm{m}^{2} /$ day to $15.75 \mathrm{MJ} / \mathrm{m}^{2} /$ day. The overall average energy is about 13.71 $\mathrm{MJ} / \mathrm{m}^{2} /$ day in a month. The average value of cloud transmittance factor is about $50.16 \%$ in a month. However there is less variation of daily solar energy in Kathmandu than in Biratnagar and Lukla but it is slightly higher variation than in Pokhara.

Figure 4.2(d) shows that there is a uniform amount of solar energy till second week of January in Lukla. After the second week there is high level of fluctuation due to the local weather condition. The solar energy varies from $6.76 \mathrm{MJ} / \mathrm{m}^{2} /$ day to $18.97 \mathrm{MJ} / \mathrm{m}^{2} /$ day. The overall average energy is about $15.43 \mathrm{MJ} / \mathrm{m}^{2} /$ day. In the given figure there is very sharp up and down lines shown because of abrupt change in the weather condition of Lukla station. In the 25th January there was overcast day and the cf is very low it is about 32.09 percent, on the other hand; on $26^{\text {th }}$ January the solar energy line sharply increased because of clear sky day and the sufficient amount of cf. 


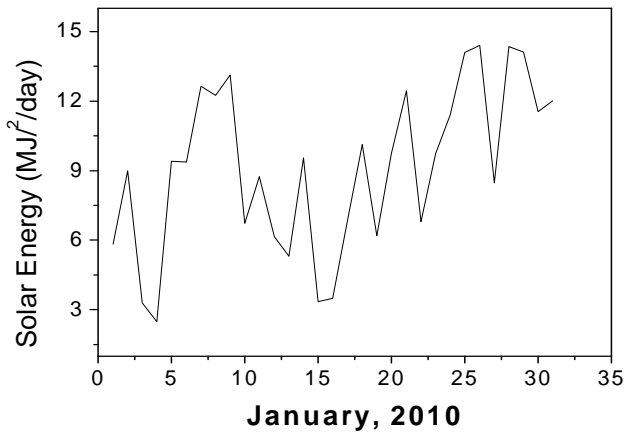

(a) Biratnagar

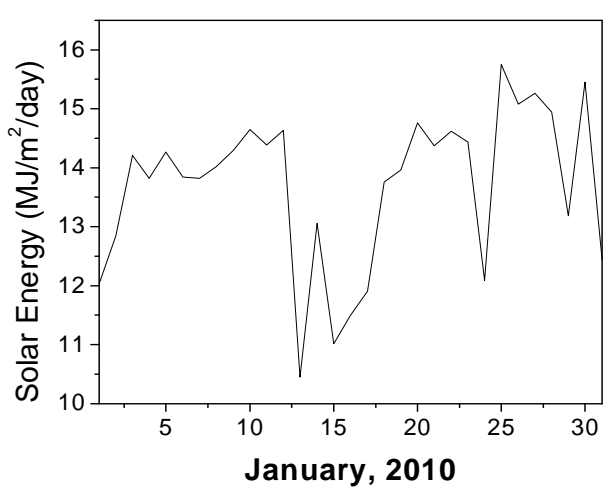

(c) Kathmandu

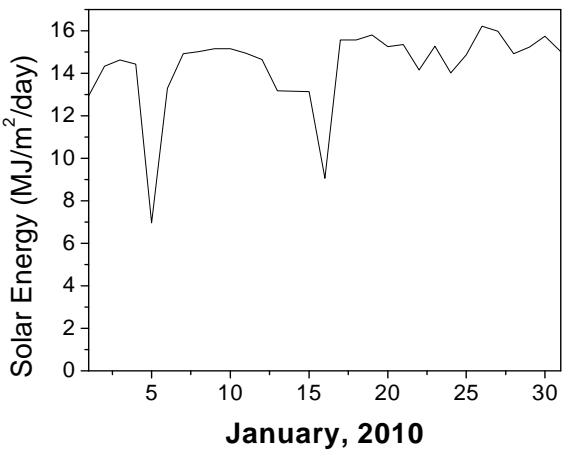

(b) Pokhara

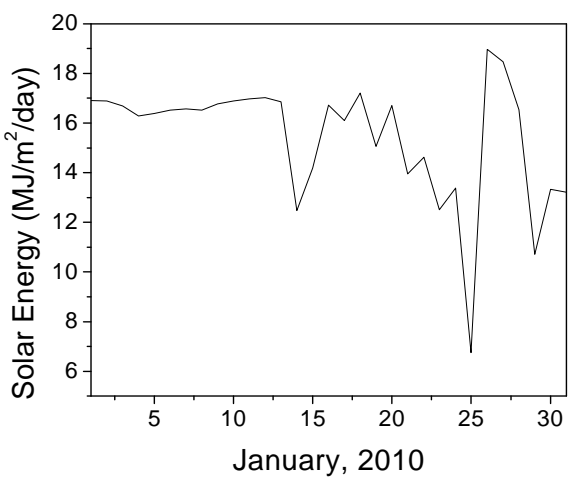

(d) Lukla

Fig. 4.2: Daily Variation of Solar Energy at four sites on January 2010

\subsection{Total Solar Energy at Different Altitude}

Figure 4.3 shows the solar energy observed in the clear sky day on $26^{\text {th }}$ January, 2010 in Biratnagar, Pokhara, Kathmandu and Lukla. The average cloud transmittance factor 47.67, 53.31, 52.98 and 70.61 percent are obtained in Biratnagar, Pokhara, Kathmandu and Lukla, respectively. About 10.79 percent, 7.43 percent and 16.12 percent more solar energy per kilometer was found in Lukla as compared to Biratnagar, Pokhara and Kathmandu respectively. This result shows that at the same date and nearly equal cf value, the solar energy is different at different altitude, it means that there is strong relationship between altitude and solar energy. It showed that the Kathmandu is highly polluted compared to Pokhara and other sites because of absorption of solar radiation by the air pollutant. Finally, it is confirmed that the solar energy varies with altitude as well as local weather condition. 


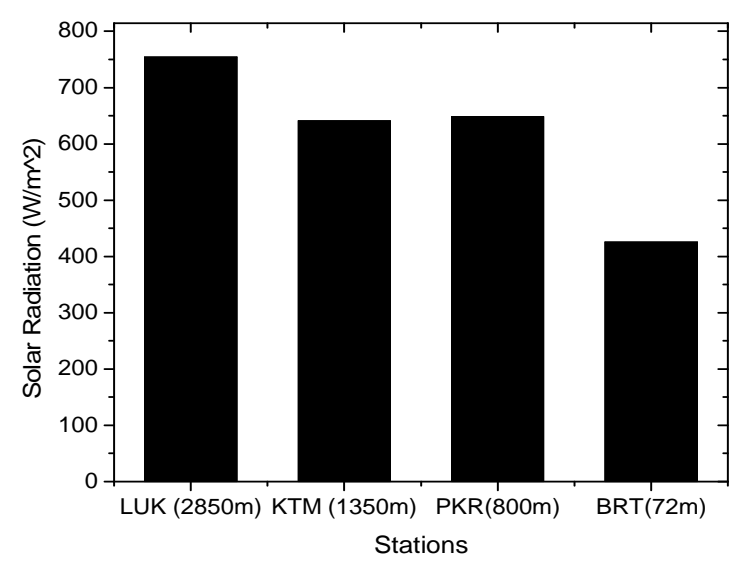

Fig.4.2: Comparative Study of Total Solar Radiation in four Sites in Clear Sky Day at noon on $26^{\text {th }}$ January 2010

\subsection{Seasonal Variation of Solar Energy in four sites of Nepal}

Figure 4.4.a shows the seasonal variation of solar energy measured in Biratnagar. The solar energy 11.68, 19.47, 21.49 and $18.68 \mathrm{in} \mathrm{MJ} / \mathrm{m}^{2} /$ day are found in Biratnagar in winter, spring, summer and autumn respectively. The average cloud transmittance factors (cf) 53.98, 64.34, 63.19 and 67.82 percent are obtained at winter, spring, summer and autumn season.

Figure 4.4.b shows the seasonal variation of solar energy measured in Pokhara and there is 13.29 $\mathrm{MJ} / \mathrm{m}^{2} /$ day, $22.83 \mathrm{MJ} / \mathrm{m}^{2} /$ day, $24.32 \mathrm{MJ} / \mathrm{m}^{2} /$ day, and $17.94 \mathrm{MJ} / \mathrm{m}^{2} /$ day solar energy found in winter, spring, summer and autumn respectively. The average cloud transmittance factors 55.69, 53.52, 63.19 and 65.51 percent are obtained in winter, spring, summer and autumn season. It indicates that the solar energy varies with $\mathrm{cf}$ as well as local weather condition.

Figure 4.4.c shows the seasonal variation of solar energy measured in Kathmandu. The solar energy amounts to $13.00,20.86,24.76$ and $15.48 \mathrm{MJ} / \mathrm{m}^{2} /$ day in Kathmandu in winter, spring, summer and autumn respectively. The average cloud transmittance factors 69.76, 57.28, 69.88 and 81.49 percent are observed in winter, spring, summer and autumn season. It shows that the intensity of solar radiation available increases with the increase in altitude. This is obvious because as we go up, there is less atmosphere available to reduce solar intensity. But in the case of Kathmandu, it is noticed that air pollutants reduce solar radiation so lesser amount of solar radiation is found in Kathmandu than at Pokhara.

Figure 4.4.d shows the seasonal variation of solar energy measured in Lukla. This site represents the High Mountain regions of Nepal. It is clear that the intensity of solar radiation increases with increase in altitude. The solar energy 16.24, 23.44, 14.96 and 10.22 in $\mathrm{MJ} / \mathrm{m}^{2} /$ day are found in Lukla in winter, spring, summer and autumn respectively. This result shows that the spring has clearer sky days whereas summer and autumn days are cloudy. But in Biratnagar, Pokhara and Kathmandu the maximum amount of energy is found in summer season. This trend is quite different from other three monitoring sites because of local weather condition. The average cloud transmittance factors (cf) 84.14, 63.81, 35.42.19 and 55.53 percent are obtained in winter, spring, summer and autumn season. 


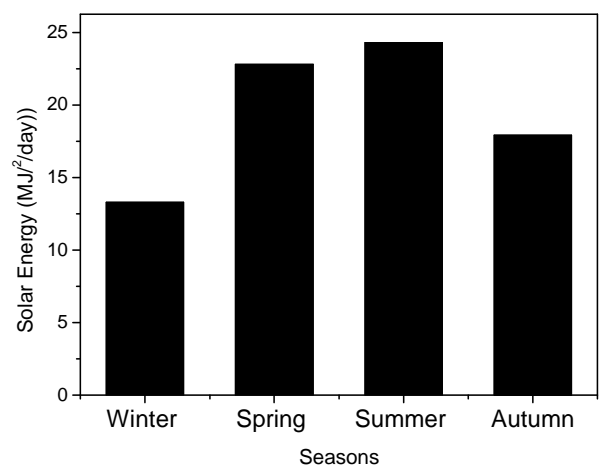

Fig.4.4.a: Biratnagar

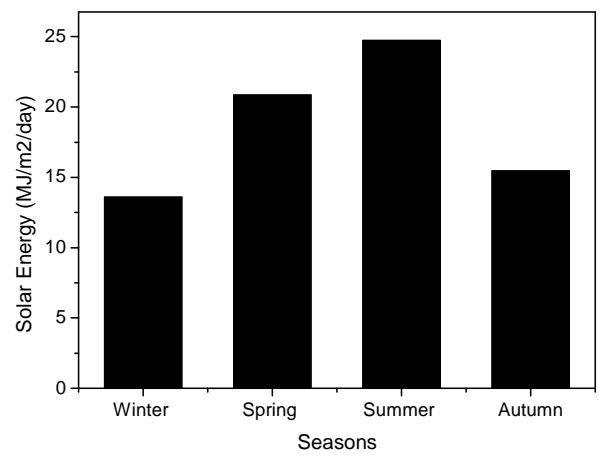

Fig.4.4.c: Kathmandu

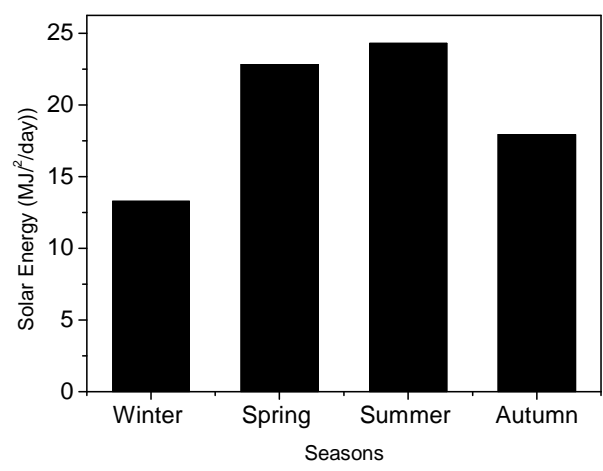

Fig.4.4.b: Pokhara

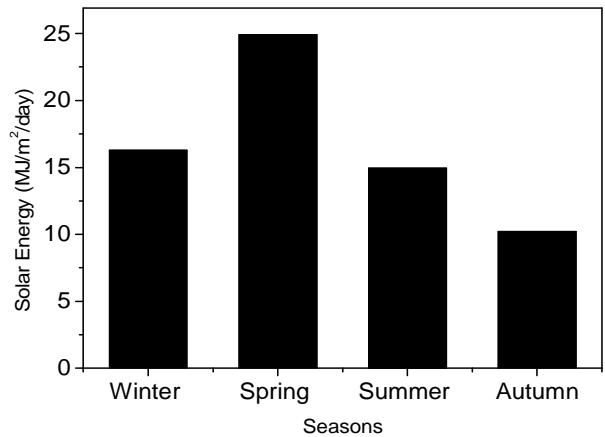

Fig. 4.4.d: Lukla

Fig.4.4: The Seasonal Variation of Total Solar Energy at

Biratnagar, Pokhara, Kathmandu and Lukla

on first week of each month of 2009 and 2010

\section{Conclusion}

It is concluded that the solar radiation varies with seasons. The total solar energy was higher in summer than in winter season in Biratnagar, Pokhara and Kathmandu, but the maximum solar energy was found in spring season at Lukla. The diurnal variation of solar radiation varies with day of the year as well as altitude. Similarly, maximum amount of solar energy is found at maximum altitude at Lukla and the minimum energy is found at the lowest altitude in Biratnagar at the same time as well as nearly equal cloud transmittance factor. But there are more cloudy days in Lukla as compared to other stations. As a result, annual average value of solar radiation is lower. Thus topography as well as local weather conditions is the most important factor that controlled the available solar radiation. 


\section{Acknowledgements}

Authors are grateful to express thanks to Solar Radiation and Aerosol in Himalaya Region (SAHR) project of IOE Pulchowk (Nepal) for providing the data of Pyranometer and other necessary supports. The support provided by the faculty members of department of Engineering Science and Humanities, Pulchowk Campus is highly acknowledged.

\section{REFERENCES}

[1] Becker C. F., James B S., Solar Radiation Availability on Surfaces Orientation, Latitude, Altitude, and Cloudiness pp17.

[2] Bhandari T. M., Report on "Role of Solar Photovoltaic Water Pumping System in Water Supply", Bhaktapur Branch Office Nepal Water Supply Corporation, 1996.

[3] CES, "Solar Mapping in Nepal", Final Report, Center for Energy Studies, Institute of Engineering, Tribhuvan University, Latitpur, Nepal, 2001.

[4] Høiskar B. A. K., Haugen R., Danielsen T., Kylling A., Edvardsen K., Dahlback A. Johnsen B., Blumthaler M., Schreder J., Multichannel, moderate bandwidth filter instrument for measurement of the ozone - column amount, cloud transmittance, and ultraviolet dose rates, Applied Optics, 42, 2003.

[5] Iqbal M., An introduction to solar radiation, Academic Press, New York, 1983.

[6] Kipp and Zonen, Instruction Manual, 2008.

[7] Masato O. and Shiinaighth H., International IBPSA Conference Eindhoven, Netherlands, Preliminary study on an Estimation Method for annual Solar Irradiance at Various Geographical Altitudes, 2003.

[8] Sapkota B. K., Environ, Vision Youth Urban Air Pollution: Issues, Impact and Mitigation, 2009.

[9] Sukhera M. B. and Pasha M. A. R., Solar Radiation Maps for Pakistan, Department of Physics, Islamia University, Bahawalpur, Pakistan Solar \& Wind Technology, 4, 2, pp. $229-238,1987$.

[10] SWERA, United Nation Environment Program: Global Environment Facility (UNDP/GEF), Solar and Wind Energy Resource Assessment in Nepal (SWERA) project, Government of Nepal, Ministry of Environment, Science and Technology, Nepal, 2006. 